\title{
Correspondence
}

\section{Value of ultrasound in differentiating causes of persistent vomiting in infants}

Sir,

The practice of neonatal cranial ultrasound was essentially developed by paediatricians. Obstetric ultrasound similarly in its early stages was the preserve of the obstetrician and in many hospitals the responsibility for provision of this service remains shared by clinician and radiologist. Such developments arose mostly from lack of radiological resources and partly admittedly from disinterest of radiologists.

It has become evident recently that some neonatologists, in particular, are using ultrasound for the evaluation of abdominal pathology, for example, in differentiating causes of persistent vomiting in infants. Demarcation disputes can be counter-productive but many radiologists view this change of practice with considerable anxiety and disapproval.

Errors of observation and interpretation will be made by incompletely trained ultrasonologists and these will be compounded by failure to appreciate the particular place of other imaging techniques. Moreover, if hard copies of images are made these become part of the patient's records and as such can constitute with any report thereon tangible evidence should litigation arise. The occasional ultrasonographer would then have to justify his or her competence (or incompetence!).

Ideally, radiological procedures in their broad definition should be left to radiologists. If radiological resources are insufficient, ask for more.

D SHAW

Department of Paediatric Radiology, Hospital for Sick Children, Great Ormond Street, London WCIN $3 J H$ referred to me by their general practitioners for counselling. All had long histories of significant psychiatric problems that dated back to childhood and had records of poor school performance and truancy. Three had been admitted to hospital under the age of 15 years with self poisoning. All six disclosed serious childhood sexual abuse. None would contemplate referral to either social services or psychiatry as both agencies had been involved in the past.

What interested me was the clarity of recall of the three who had made suicidal attempts, and the remarkable consistency of their perceptions of these events. 'The psychiatrists seemed more interested in my parents.' 'They just sent me straight back home'. ' $\mathrm{He}$ (the abuser) just sat there all day-it was worse than being at home.' 'They wouldn't have believed me anyway.' 'They told them (parents) that I didn't really mean it.'

Dr Clarke acknowledges that sexual abuse has been underestimated in the statistics. I would suggest that this factor may be of very serious significance in the background of large numbers of self poisoning adolescents and that poor compliance with follow up must be viewed in the context of professional failure to recognise this and act accordingly.

The women who spoke to me perceived the standard psychiatric approach (that is, rapid assessment, early discharge, close involvement of parents) as a betrayal of their interests. Dr Clarke proposes no way by which young victims of chronic sexual abuse can be helped to individuate or feel safe. To blame the victim for poor compliance and simply propose more of the medicine that fails seems to me most unhelpful. One woman I spoke to appeared to be more hostile towards and angry about the psychiatrist than the perpetrator of the abuse.

\section{Reference}

${ }^{1}$ Clarke, CF. Deliberate self poisoning in adolescents. Arch Dis Child 1988;63:1479-83.

C Lazaro

Department of Child Health, Royal Victoria Infirmary, Newcastle upon Tyne NE1 4LP

\section{Diagnosis of brain death by transcranial Doppler sonography}

Sir,

The paper published from Freiburg by Bode et al points to 